\title{
Risk factors for bronchiolitis hospitalization during the first year of life in a multicenter Italian birth cohort
}

\author{
Marcello Lanari ${ }^{1}$, Federica Prinelli ${ }^{2,3}$, Fulvio Adorni ${ }^{2}$, Simona Di Santo ${ }^{4}$, Silvia Vandini ${ }^{*}$, Michela Silvestri ${ }^{6}$, \\ Massimo Musicco ${ }^{2,4}$ and and the Study Group of Italian Society of Neonatology on Risk Factors for RSV \\ Hospitalization
}

\begin{abstract}
Background: Respiratory Syncytial Virus (RSV) is one of the main causes of respiratory infections during the first year of life. Very premature infants may contract more severe diseases and 'late preterm infants' may also be more susceptible to the infection.

The aim of this study is to evaluate the risk factors for hospitalization during the first year of life in children born at different gestational ages in Italy.

Methods: A cohort of 33-34 weeks gestational age (WGA) newborns matched by sex and age with two cohort of newborns born at 35-37 wGA and > 37 wGA were enrolled in this study for a three-year period (2009-2012). Hospitalization for bronchiolitis (ICD-9 code 466.1) during the first year of life was assessed through phone interview at the end of the RSV season (November-March) and at the completion of the first year of life.

Results: The study enrolled 2314 newborns, of which 2210 (95.5\%) had a one year follow-up and were included in the analysis; 120 (5.4\%) were hospitalized during the first year of life for bronchiolitis. Children born at 33-34 wGA had a higher hospitalization rate compared to the two other groups. The multivariate analysis carried out on the entire population associated the following factors with higher rates for bronchiolitis hospitalization: male gender; prenatal treatment with corticosteroids; prenatal exposure to maternal smoking; singleton delivery; respiratory diseases in neonatal period; surfactant therapy; lack of breastfeeding; siblings < 10 years old; living in crowded conditions and/or in unhealthy households and early exposure to the epidemic RSV season. When analysis was restricted to preterms born at 33-34 wGA the following variables were associated to higher rates of bronchiolitis hospitalization: male gender, prenatal exposure to maternal smoking, neonatal surfactant therapy, having siblings $<10$ years old, living in crowded conditions and being exposed to epidemic season during the first three months of life.
\end{abstract}

Conclusion: Our study identified some prenatal, perinatal and postnatal conditions proving to be relevant and independent risk factors for hospitalization for bronchiolitis during the first year of life. The combination of these factors may lead to consider palivizumab prophylaxis in Italy.

Key words: Bronchiolitis, Hospitalization, Risk factor, Respiratory syncytial virus, Prophylaxis, Palivizumab, Children

\footnotetext{
* Correspondence: silviavandini@gmail.com

${ }^{5}$ Neonatology Unit S.Orsola-Malpighi Hospital, Via Massarenti 11, Bologna, Italy

Full list of author information is available at the end of the article
} 


\section{Background}

Bronchiolitis is the first cause of hospitalization of infants in the USA and it is the most frequent lower respiratory tract disease in preterm infants [1-4].

Infants with chronic lung disease (CLD), congenital heart disease (CHD), immunodeficiency and neuromuscular disorders are particularly at high risk of hospitalization for bronchiolitis [5]. Moreover, preterm infants [6] are also more prone to these infections due to the impaired development of the lung and of the immune system. In particular, it has been observed that prematurity has been associated to an increased likelihood of hospitalization for RSV bronchiolitis [1].

Studies performed in Europe and in the USA have also shown that infants born between 33 and 35 wGA have a higher risk of hospitalization due to RSV infections than full-term infants $[1,7,8]$. This population is at risk of developing severe RSV infection that can result in morbidity and yield similar expenditures to infants born before 33 wGA $[1,9,10]$. Several studies have found other determinants of bronchiolitis and in particular of severe diseases caused by RSV [11], however, two of the largest studies carried out on cohort of infants born at these gestational ages [12-14] reported inconclusive results, probably due to the methodologic approach and differences in context (i.e.social, epidemic, climatic) [8].

In Italy, a multicenter study enrolling over 1200 children younger than two years hospitalized for lower respiratory tract infections (LRTI) found that two-thirds of hospitalizations occurred in children with low birth weight and low gestational age, with an incidence $8.5 \%$ in infants born before 36 weeks vs. $4 \%$ in the general population [15]. Moreover, among children with bronchiolitis, RSV infection was particularly frequent in those born at lower gestational age. Among the patients who were RSVpositive, $60.0 \%$ were born at a gestational age of 33 weeks; $59.1 \%$ between $34-35 \mathrm{wGA}$; and $47.4 \%$ at more than 35 wGA [15]. This study found that passive tobacco smoke exposure increased the rate of hospitalization for RSV infections (RR 1.4). Moreover, RSV positivity was related to birth order, since it was higher in infants with a larger number of siblings [15].

The aim of the current study is to evaluate the role of prenatal, perinatal and postnatal conditions in determining the risk of hospitalization for bronchiolitis in a large cohort of preterm with GA 33 weeks or more and full term newborns.

In addition to that, the analysis of risk factors was focused on preterm infants born at 33-34 wGA. This population of preterm infants, although well documented to be at high risk of severe RSV infections $[1,7,8]$ has been recently crossed out from the revised AAP guidelines [16] for prophylaxis with palivizumab, a monoclonal humanized antibody neutralizing RSV. Two important studies
[12-14] analyzed the risk factors for hospitalization in these preterm infants; however, the analysis of risk factors in a large Italian birth cohort has not yet been performed. The determination of national risk factors could improve the capacity to detect newborns at particularly high risk for severe respiratory infection and hospitalization that may be considered for a "tailored" prophylaxis treatment. In Italy prophylaxis with palivizumab is regulated by the Italian Neonatology Society guidelines [17], but they are widely disregarded especially in preterm infants born at 33 wGA or more. The Italian Neonatology Society is reviewing these recommendations through the update of the epidemiological data.

The results of the present multicenter study and the analysis of the risk factors will be considered by the Italian Neonatology Society for the update of the guidelines.

\section{Methods}

This is a multicenter cohort study including consecutive newborns born between 2009 and 2012. All subjects were enrolled at birth and followed up for the first year of life.

Thirty Neonatology Units from hospitals with 1000 or more deliveries per year located in the northern, central, southern and insular regions of Italy participated in this study. Ethic Committees of each participating hospital approved the study protocol. A written consent was obtained from legal guardians of all patients.

For each enrolled newborn of 33-34 wGA, two further newborns of the same sex and with the nearest date of birth were enrolled: one of 35-37 wGA and one of $>37$ wGA.

Exclusion criteria were life expectancy shorter than six months; haemodynamically significant congenital heart diseases and chronic lung diseases (defined as oxygen requiring at 28 days of life [18]); concurrent enrolment in another trial; programmed or administered RSV prophylaxis with palivizumab and inability to follow up at our center during the study period.

In each center, the enrolling physician filled out a record with prenatal and perinatal data after checking inclusion and exclusion criteria, within two days after the births.

In order to detect possible occurrence of respiratory infections (leading to hospitalization or not), after enrolment a structured phone interview was carried out twice with the parents by a trained interviewer from the Italian National Research Council (CNR). The first interview was carried out at the end of the epidemic RSV season (at end of March in Italy [19]) and the second one at 12 months of age. During the phone interview, postnatal data on potential risk factors such as lack of breastfeeding, exposure to environmental pollution and/or to passive cigarette smoke were recorded.

When parents reported hospitalization of the child for any cause, the enrolling physician collected all the relevant 
clinical and therapeutic information from the hospital clinical record forms.

The primary outcome was the occurrence of hospitalization/death for bronchiolitis during the first year of life. Hospitalizations for bronchiolitis were defined according to the hospital discharge form with the ICD-9 codes 466.1 (acute bronchiolitis).

Table 1 reports the variables registered by the enrolling physicians and from the interviews concerning neonatal, perinatal and postnatal variables potentially associated to bronchiolitis.

Low level of parental education was defined as no education or primary education (vs. secondary or higher).

Presence of maternal diseases during pregnancy was identified when the mother suffered from chronic conditions or other disorders affecting the pregnancy outcome such as hypertension, preeclampsia or diabetes mellitus.

Table 1 Baseline demographic and clinical characteristic of the enrolled newborns and of their parents: prenatal conditions

\begin{tabular}{|c|c|c|c|c|}
\hline & \multicolumn{4}{|l|}{ wGA groups } \\
\hline & $33^{+0 d_{-}} 4^{+6 d}($ No. 737$)$ & $35^{+0 \mathrm{~d}}-37^{+6 \mathrm{~d}}(\mathrm{No} .767)$ & $\geq 38^{+0 d}($ No. 706$)$ & Total (No. 2210) \\
\hline \multicolumn{5}{|l|}{ Pregnancy } \\
\hline Assisted reproductive technique & $154(20.9)$ & $90(11.7)$ & $7(1.0)$ & $251(11.4)$ \\
\hline Intrauterine growth restriction (IUGR) & $82(11.1)$ & $58(7.6)$ & $7(1.0)$ & $147(6.7)$ \\
\hline \multicolumn{5}{|l|}{ Mother's characteristics } \\
\hline Age $>40$ year & $95(12.9)$ & $91(11.9)$ & $46(6.5)$ & $232(10.5)$ \\
\hline Low education & $185(25.1)$ & $184(24)$ & $131(18.6)$ & $500(22.6)$ \\
\hline \multicolumn{5}{|l|}{ Nationality } \\
\hline Italian & $654(88.7)$ & $703(91.7)$ & $655(92.8)$ & $2012(91.0)$ \\
\hline African & $12(1.6)$ & $9(1.2)$ & $8(1.1)$ & $29(1.3)$ \\
\hline Asian & $10(1.4)$ & $2(0.3)$ & $6(0.8)$ & $18(0.8)$ \\
\hline Eastern Europe & $36(4.9)$ & $37(4.8)$ & $22(3.1)$ & $95(4.3)$ \\
\hline Western Europe & $13(1.8)$ & $4(0.5)$ & $7(1.0)$ & $24(1.1)$ \\
\hline Southern America & $12(1.6)$ & $12(1.6)$ & $8(1.1)$ & $32(1.4)$ \\
\hline Maternal diseases during pregnancy & $275(37.3)$ & $220(28.7)$ & $92(13.0)$ & $587(26.6)$ \\
\hline Treatment with corticosteroids & $404(54.8)$ & $157(20.5)$ & $4(0.6)$ & $565(25.6)$ \\
\hline History of respiratory diseases & $138(18.7)$ & $134(17.5)$ & $132(18.7)$ & $404(18.3)$ \\
\hline Asthma & $49(6.6)$ & $50(6.5)$ & $47(6.7)$ & $146(6.6)$ \\
\hline COPD & $12(1.6)$ & $8(1.0)$ & $6(0.8)$ & $26(1.2)$ \\
\hline Eczema & $33(4.5)$ & $28(3.7)$ & $26(3.7)$ & $87(3.9)$ \\
\hline Rhinitis & $78(10.6)$ & $82(10.7)$ & $90(12.7)$ & $250(11.3)$ \\
\hline Wheezing & $1(0.1)$ & - & $1(0.1)$ & $2(0.1)$ \\
\hline \multicolumn{5}{|l|}{ Prenatal smoke exposure } \\
\hline None & $559(75.8)$ & $560(73.0)$ & $525(74.4)$ & $1644(74.4)$ \\
\hline To maternal active smoking only & $76(10.3)$ & $93(12.1)$ & $61(8.6)$ & $230(10.4)$ \\
\hline To maternal passive smoking only & $102(13.8)$ & $114(14.9)$ & $120(17.0)$ & $336(15.2)$ \\
\hline \multicolumn{5}{|l|}{ Father's characteristics } \\
\hline Age $>40$ year & $184(25.0)$ & $203(26.5)$ & $158(22.4)$ & $545(24.7)$ \\
\hline Low education & $219(29.7)$ & $261(34.0)$ & $198(28.0)$ & $678(30.7)$ \\
\hline History of respiratory diseases & $138(18.7)$ & $158(20.6)$ & $141(20.0)$ & $437(19.8)$ \\
\hline Asthma & $51(6.9)$ & $48(6.3)$ & $48(6.8)$ & $147(6.7)$ \\
\hline COPD & $8(1.1)$ & $14(1.8)$ & $8(1.1)$ & $30(1.4)$ \\
\hline Eczema & $15(2.0)$ & $12(1.6)$ & $15(2.1)$ & $42(1.9)$ \\
\hline Rhinitis & $100(13.6)$ & $133(17.3)$ & $117(16.6)$ & $350(15.8)$ \\
\hline
\end{tabular}

All data are reported as No. (\%).wGA = weeks of gestational age; yrs = years 
The presence of parental asthma, COPD and wheezing was recorded when the parents reported to have previously received the diagnosis by other physicians.

A baby was considered small for gestational age (SGA) if smaller than normal for the gestational age, most commonly defined as a weight below the $10^{\text {th }}$ percentile for gestational age, according to the Italian neonatal anthropometric charts [20].

The presence of siblings in the household of the child was defined as $\geq 1$ sibling younger than 10 years living $\geq 3$ days per week in the same house. A crowded living condition was defined as $\geq 5$ inhabitants per household excluding the study subject and his/her siblings less than 10 years old.

Breastfeeding was evaluated combining the information collected at hospital discharge and that derived from the two follow up interviews, and was defined as feeding with maternal milk (exclusively or associated with formula), either from breast or bottle. Children were first classified as 'never breastfed' or 'ever breastfed', and children 'ever breastfed' were further classified according to having been fed exclusively with maternal milk or with both maternal milk and formula together.

Pollution exposure (i.e. residence in the proximity of intense traffic areas) and indoor humidity exposure (i.e. visible mold growth) were registered according to interviews. Exposure to epidemic season was defined as living for at least one month of their first three months of life from November to March.

Sample size was calculated by fixing a predefined precision of the estimate of the absolute risk of hospitalization and/or death for RSV-induced or non RSV-induced bronchiolitis during the first year of life. Assuming that the risk of hospitalization for bronchiolitis during the first year of life was about $7 \%$, a sample size of 2500 newborns could provide a $95 \%$ confidence interval $(95 \% \mathrm{CI})$ of 6.0 to $8.1 \%$ that is largely consistent with a random error of less than $20 \%$.

The probability of bronchiolitis-related hospitalization was considered as a time-dependent variable, and a survival analysis was carried-out using Cox proportional hazard models to calculate the cumulative timedependent risks. Relative risks were estimated as hazard ratios and $95 \%$ confidence limits were derived from the standard errors of the parameter estimated by the model.

Crude hazard ratios were calculated for all the considered variables. Multivariable analyses were carried-out first on all the variables grouped within each set of pre-, peri-, and post-natal risk factors. All the variables significantly associated with the risk of hospitalization for bronchiolitis in these initial multivariable analyses entered into the final regression model.

Analyses were carried out using SPSS software package version 20.0 (IBM Corporation 2010; IBM SPSS Statistics for Windows).

\section{Results}

In a three-year period, 2314 healthy newborns were enrolled. Out of those 2210 (95.5\%) of which 1150 male and 1060 female underwent a one year follow-up and were included in the analysis; 104 were lost to follow-up and were excluded. No infants died during the follow-up period.

Baseline demographic and clinical characteristics of the enrolled newborns and their parents by gestational age are reported in Tables 1, 2 and 3.

Conception through assisted reproductive technology, multiple births, mothers with diseases potentially harmful for the pregnancy, or who were treated with corticosteroids,

Table 2 Baseline demographic and clinical characteristic of the enrolled newborns and of their parents: perinatal/neonatal conditions

\begin{tabular}{|c|c|c|c|c|}
\hline & wGA groups & & & \\
\hline & $33^{+0 d_{-}} 34^{+6 d}(\mathrm{No} .737)$ & $35^{+0 d}-37^{+6 d}(\mathrm{No} .767)$ & $\geq 38^{+0 d}(\mathrm{No} .706)$ & Total (No. 2210) \\
\hline Male gender & $382(51.8)$ & $400(52.2)$ & $368(52.1)$ & $1150(52.0)$ \\
\hline Caesarean delivery & $607(82.4)$ & $520(67.8)$ & $262(37.1)$ & $1389(62,9)$ \\
\hline Singleton delivery & $419(56.9)$ & $552(72)$ & $702(99.4)$ & $1673(75.7)$ \\
\hline APGAR score at five minutes $<8$ & $42(5.7)$ & $22(2.9)$ & $7(1.0)$ & $71(3.2)$ \\
\hline Birth weight [g (mean, SD)] & $2031(380.9)$ & $2605.1(517.1)$ & $3296.1(423.6)$ & $2635.1(678.1)$ \\
\hline Small for gestational age (SGA) & $135(18.3)$ & $85(11.1)$ & $19(2.7)$ & $239(10,8)$ \\
\hline Resuscitation after birth & $199(27.0)$ & 109 (14.2) & $38(5.4)$ & $346(15.7)$ \\
\hline Neonatal hospitalization & $715(97.0)$ & $430(56.1)$ & $137(19.4)$ & $1282(58)$ \\
\hline Respiratory diseases & $296(40.2)$ & $121(15.8)$ & $23(3.3)$ & $440(19.9)$ \\
\hline Surfactant therapy & $48(6.5)$ & $11(1.4)$ & $1(0.1)$ & $60(2.7)$ \\
\hline Antibiotics therapy & $149(20.2)$ & $47(6.1)$ & $6(0.8)$ & $202(9.1)$ \\
\hline
\end{tabular}

All data are reported as No. (\%), unless otherwise specified; $w G A=$ weeks of gestational age 
Table 3 Baseline demographic and clinical characteristic of the enrolled newborns and of their parents: postnatal conditions

\begin{tabular}{|c|c|c|c|c|}
\hline & \multicolumn{4}{|l|}{ wGA groups } \\
\hline & $33^{+0 d}-34^{+6 d}($ No. 737$)$ & $35^{+0 d}-37^{+6 d}($ No. 767$)$ & $\geq 38^{+0 d}($ No. 706$)$ & Total (No. 2210) \\
\hline \multicolumn{5}{|l|}{ Presence of siblings } \\
\hline None & $472(64.0)$ & $444(57.9)$ & $394(55.8)$ & $1310(59.3)$ \\
\hline$\leq 10$ year & $223(30.3)$ & $289(37.7)$ & $280(39.7)$ & $792(35.8)$ \\
\hline$>10$ year & $42(5.7)$ & $34(4.4)$ & $32(4.5)$ & $108(4.9)$ \\
\hline Residential crowding & $88(11.9)$ & $86(11.2)$ & $53(7.5)$ & $227(10.3)$ \\
\hline Lack of breastfeeding & $209(28.4)$ & $193(25.2)$ & $80(11.3)$ & $482(21.8)$ \\
\hline Pollution exposure & $77(10.4)$ & $102(13.3)$ & $87(12.3)$ & $266(12.0)$ \\
\hline Exposure to parental smoking & $310(42.1)$ & $320(41.7)$ & $272(38.5)$ & $902(40.8)$ \\
\hline Indoor humidity & $75(10.2)$ & $75(9.8)$ & $72(10.2)$ & $222(10)$ \\
\hline Exposure to epidemic season & $437(59.3)$ & $474(61.8)$ & $412(58.4)$ & $1323(59.9)$ \\
\hline Hospitalization for bronchiolitis & $54(7.3)$ & $41(5.3)$ & $25(3.5)$ & $120(5.4)$ \\
\hline
\end{tabular}

All data are reported as No. (\%); $w G A=$ weeks of gestational age; $y r s=$ years

were more frequent in the group of babies born at 33-34 wGA. The babies in this group had a lower birth weight than newborns born at a longer gestational age and were more frequently SGA. In addition, they had more frequently neonatal respiratory diseases and/or received more frequently medical interventions (neonatal resuscitation in delivery room, hospitalization in neonatal department and/or in neonatal intensive care unit, surfactant and/or antibiotic therapy).

\section{Hospitalization for bronchiolitis during the first year of life}

Out of the babies who underwent follow-up at 12 months, $120(5.4 \%)$ were admitted to hospital for bronchiolitis; $65 / 120$ (54 \%) hospitalizations occurred within the first 3 months of life and 90/120 (75 \%) within the first 6 months of life. The majority of hospital admissions occurred during the RSV epidemic season and 95/120 $(87.5 \%)$ cases occurred in preterm infants, of whom $54 / 120$ (45 \%) were born at 33-34 wGA. The majority of the hospitalizations in this group occurred within the first 6 months $(43 / 54,79.6 \%)$ of life, 31/54 (57 \%) within the first 3 months of life.

Of the 120 hospitalized infants, $31 / 120$ (26\%) were tested for RSV and 26/31 (83 \%) were positive.

At univariate analysis (Table 4), the risk estimates (hazard ratios) for hospitalization for bronchiolitis increased 2 and 1.5 folds respectively for those born at 33-34 and 35-37 wGA compared to the newborns born at more than 37 wGA. Rates of bronchiolitis occurrence increased 1.6 folds for male newborns.

The prenatal, neonatal and postnatal conditions found to be significant at univariate analysis were included in the multivariate analysis (Table 4 and 5).

At univariate analysis, the prenatal conditions that significantly increased the risk of hospitalization for bronchiolitis were: father history of COPD and prenatal exposure of the mother to active or passive smoking. Mother's comorbid conditions (i.e. diabetes, hypertension) and treatment with corticosteroids showed an increased risk near statistical significance and were included in the multivariable analyses. Among the neonatal/perinatal risk factors, singleton delivery, respiratory diseases, surfactant therapy and lack of breastfeeding were associated to significantly higher risks of bronchiolitis admission at univariate analysis. Resuscitation with $\mathrm{O}_{2}$ at birth was associated with a 1.4 fold increased risk but reached only borderline statistical significance and was retained for subsequent analyses.

With regard to postnatal/environmental conditions, having siblings younger than 10 years, crowded living environment and being exposed to epidemic RSV season were associated with significantly higher rates of hospitalization. Residence in proximity of intense vehicular traffic determined a borderline statistically significant increase of risk for hospitalization for bronchiolitis and was retained for further multivariable analyses.

On multivariate analysis, a significant increase of the risk of hospitalization for bronchiolitis in the entire cohort was associated to male gender; prenatal treatment with corticosteroids; tobacco smoke exposure during pregnancy; singleton delivery; respiratory disorders and administration of surfactant at birth, lack of breastfeeding; siblings younger than 10 years; crowded living conditions and exposure to household humidity and exposure to epidemic season (Table 4).

Subgroup analysis on the group of preterm born at 3334 wGA revealed that the significant risk factors partially differ from the results of the analysis performed on the entire group. At univariate analysis in this particular group, the significant risk factors for hospitalization for bronchiolitis are summarized in Table 5. At multivariate analysis only six factors maintained statistical significance: male gender; prenatal exposure to maternal smoking; neonatal 
Table 4 Relative risks estimates (hazard ratios) according to prenatal, neonatal/perinatal and postnatal/environmental conditions for hospitalization

\begin{tabular}{|c|c|c|c|}
\hline \multirow[t]{2}{*}{ Exposures } & \multicolumn{2}{|c|}{ Bronchiolitis hospitalization +/- exposed (\%) } & \multirow[t]{2}{*}{ Multivariable $\mathrm{HR}^{\mathrm{a}}\left(95 \%^{\mathrm{b}}\right.$ ) } \\
\hline & Events/unexposed & Events/exoposed [HR', $95 \% \mathrm{Cl}]$ & \\
\hline Gender-male & $44 / 1060(4.2)$ & $76 / 1150(6.6)[1.6,1.1-2.3]$ & $1.6(1.1-2.4)$ \\
\hline \multicolumn{4}{|l|}{ Week of gestational age } \\
\hline $33-34$ vs $>37$ & $25 / 706(3.5)$ & $54 / 737(7.3)[2.1,1.3-3.4]$ & \\
\hline $35-37$ vs > 37 & $25 / 706(3.5)$ & $41 / 767(5.3)[1.5,0.9-2.5]$ & \\
\hline \multicolumn{4}{|l|}{ Prenatal } \\
\hline Mother's history of BPCO & $117 / 2184(5.4)$ & $3 / 26(11.5)[2.2,0.7-6.9]$ & \\
\hline Mother's history of eczema & $113 / 2123(5.3)$ & 7/87 (8.0) $[1.6,0.7-3.4]$ & \\
\hline Father's history of BPCO & $115 / 2180(5.3)$ & $5 / 30(16.7)[3.6,1.5-8.9]$ & \\
\hline Assisted reproductive technology & 115/1959 (5.9) & $5 / 251(2.0)[0.3,0.1-0.6]$ & \\
\hline Treatment with corticosteroids & 75/1645 (4.6) & $45 / 565(8.0)[1.4,0.9-2.2]$ & $1.6(1.1-2.4)$ \\
\hline Mother's pregnancy pathologies & 78/1623 (4.8) & $42 / 587(7.2)[1.4,0.9-2.0]$ & \\
\hline Prenatal smoke exposure & $58 / 1358(4.3)$ & $62 / 852(7.3)[1.8,1.2-2.5]$ & $1.6(1.1-2.3)$ \\
\hline \multicolumn{4}{|l|}{ Neonatal/Perinatal } \\
\hline \multicolumn{4}{|l|}{ Delivery } \\
\hline Singleton & 23/537 (4.3) & $97 / 1673(5.8)[1.9,1.2-3.0]$ & $1.8(1.1-2.9)$ \\
\hline Resuscitation with $\mathrm{O}_{2}$ & 95/1911 (5.0) & $25 / 299(8.4)[1.4,0.9-2.3)]$ & \\
\hline \multicolumn{4}{|l|}{ Perinatal } \\
\hline Neonatal hospitalization & $83 / 1770(4.7)$ & $37 / 440(8.4)[1.5,1.0-2.2]$ & $1.6(1.0-2.5)$ \\
\hline Surfactant therapy & $109 / 2150(5.1)$ & $11 / 60(18.3)[3.8,1.6-5.8]$ & $2.0(1.1-3.8)$ \\
\hline \multicolumn{4}{|l|}{ Postnatal (environmental) } \\
\hline Having siblings $<10$ years & $40 / 1310(3.1)$ & $73 / 792(9.2)[3.3,2.2-4.8]$ & $3.0(2.0-4.5)$ \\
\hline$\geq 10$ years & $40 / 1310(3.1)$ & $7 / 108(6.5)[2.2,1.0-5.0]$ & $1.9(0.9-4.4)$ \\
\hline \multicolumn{4}{|l|}{ Environmental (home) conditions } \\
\hline Residential crowding & 93/1983 (4.7) & $27 / 227(11.9)[2.6,1.7-3.9]$ & $2.4(1.5-3.7)$ \\
\hline Indoor humidity & 101/1988 (5.1) & $19 / 222(8.6)[1.7,1.0-2.8]$ & $1.6(1.0-2.6)$ \\
\hline Heating system generating smoke & $90 / 1742(5.2)$ & $30 / 468(6.4)[1.2,0.8-1.8]$ & \\
\hline Residence in the proximity of intense vehicular traffic roads & $100 / 1926(5.2)$ & $20 / 284(7.0)[1.4,0.9-2.3]$ & \\
\hline Sibilings & $63 / 1414(4.5)$ & $57 / 796(7.2)[1.6,1.1-2.3]$ & \\
\hline Lack of breastfeeding & 78/1728 (4.5) & $42 / 482(8.7)[1.8,1.2-2.6]$ & $1.8(1.2-2.6)$ \\
\hline Passive cigarette smoke exposure & 112/2102 (5.3) & $8 / 108$ (7.4) $[1.5,0.7-3.1]$ & \\
\hline Exposed to epidemic RSV season & $31 / 887(3.5)$ & $89 / 1323(6.7)[2.0,1.3-3.0]$ & $1.9(1.3-2.9)$ \\
\hline
\end{tabular}

${ }^{a}$ Estimates from a model including all significant variables at gender and weeks of gestational age adjusted analysis

b95 \% Confidence Interval

${ }^{\mathrm{c}}$ Hazard ratios estimates adjusted for gender and weeks of gestational age

surfactant therapy; having siblings younger than 10 years old, living in crowded conditions and exposure to epidemic RSV season (Table 5).

\section{Discussion}

This study on infants born at 33 wGA or more provides an updated report on hospitalizations for bronchiolitis within an Italian network of thirty Neonatology and Pediatric Units in a large longitudinal birth cohort. When analyzing the entire cohort, we found that about
$5 \%$ of the newborns were admitted to hospital for bronchiolitis during their first year of life as well as preterm infants born at 33-34 wGA had a higher risk of hospitalization compared to those born at $\geq 35 \mathrm{wGA}$. The criteria for hospitalization in Italy were previously proposed by several pediatric scientific society and have been summarized in an inter-society consensus document in 2014 [21]. The indications to hospitalization include clinical evaluation and analysis of pre-existing risk factors such as prematurity, congenital heart diseases or 
Table 5 Relative risks estimates (hazard ratios) of hospitalization for bronchiolitis in $33^{+0 d}-34^{+6 d}$ wGA newborns

\begin{tabular}{|c|c|c|}
\hline & Crude HR $(95 \%$ Cl) & Adjusted HR (95\% Cl) \\
\hline \multicolumn{3}{|l|}{ Prenatal Conditions } \\
\hline Assisted reproductive technology & $0.3(0.1-0.8)$ & \\
\hline Prenatal smoke exposure & $1.9(1.1-3.3)$ & $2.0(1.2-3.5)$ \\
\hline \multicolumn{3}{|l|}{ Neonatal Conditions } \\
\hline Male gender & $1.6(1.1-2.3)$ & $1.6(1.0-2.7)$ \\
\hline Singleton & $1.7(1.1-3.0)$ & \\
\hline Apgar in the first 5 min $<8$ & $2.2(1.1-4.9)$ & \\
\hline Birth weight in $\mathrm{g}$ & $1.0(1.0-1.0)$ & \\
\hline Surfactant therapy & $3.8(2.0-7.4)$ & $3.1(1.6-6.0)$ \\
\hline Antibiotic therapy & $2.0(1.1-3.5)$ & \\
\hline \multicolumn{3}{|l|}{ Postnatal Conditions } \\
\hline Presence of siblings $\leq 10$ year & $3.8(2.1-6.6)$ & $3.2(1.8-5.7)$ \\
\hline Residential crowding & $3.0(1.7-5.5)$ & $2.9(1.6-5.4)$ \\
\hline Indoor humidity & $1.9(1.1-3.8)$ & \\
\hline Exposure to epidemic season & $1.8(1.0-3.0)$ & $1.8(1.0-3.3)$ \\
\hline
\end{tabular}

wGA = weeks of gestational age; $\mathrm{HR}=$ hazard risk; $95 \% \mathrm{Cl}=95 \%$ confidence interval; yrs = years

chronic diseases. Given the presence of shared national guidelines, the decision to hospitalize an infant to be derived from the analysis of all the individual criteria. Male gender, prenatal conditions (treatment with corticosteroids and exposure to tobacco smoking), neonatal conditions (singleton delivery, respiratory diseases, surfactant therapy) and environmental/postnatal conditions (lack of breastfeeding, having siblings $<10$ years old, crowded and unhealthy living conditions and being exposed to epidemic RSV season) were associated with a significant increase of hospitalization rate for bronchiolitis in the entire birth cohort.

The same analysis repeated in the group of infants born at 33-34 wGA proved that prenatal smoke exposure, male gender, surfactant therapy, presence of siblings $<10$ years, crowded living conditions and exposure to epidemic RSV season are statistically significant risk factors for hospitalization for bronchiolitis.

The results of our analyses were adjusted for wGA, when referring to the whole cohort, or restricted to 3334 wGA infants. According to this, our results point out that, beyond to postnatal exposures (independent from wGA), pre- and peri-natal risk factors are associated to conditions of clinical severity differently prevalent in premature or non-premature infants, so that prematurity "per se" is not to be considered a predictor.

Although severe diseases are more common among children with prematurity, CLD, CHD and other pathologic conditions, more than half of babies hospitalized for RSV infections during the first year of life [1] and $80 \%$ of RSV-related deaths occur among children who do not have an underlying clinical high-risk condition
$[4,22]$. This suggests that environmental or other conditions enforce the risk condition due to prematurity and pre-existing diseases, determining an additional increase of the risk $[23,24,10]$.

Our results only partially agree with other studies. These disagreements seem intrinsic to the nature of cohort studies, moreover when carried out in different settings and with different methodologies. We can hypothesize that study procedures, different populations, data collection, variable definitions and follow-up duration may have played a role in determining partially different results.

Male sex is known to be a risk factor for severe RSV bronchiolitis $[23,14]$ with a risk ratio of boys to girls being 1.425:1 [23].

It is also well known that smoking in pregnancy is associated with reduced lung function of the newborn [25-27]. In a large case-control study from Denmark [28] that was designed to evaluate risk factors for RSV hospitalization in infants younger than 2 years, prenatal exposure to smoking was one of the significant factors on multivariate analysis (odds ratio: 1.56; $95 \%$ CI: 1.32-1.98).

In our study, prenatal corticosteroid administration and singleton birth were observed to increase the risk for hospitalization for bronchiolitis. These data are discordant with previous studies and require further confirmation [29, 30].

A perinatal/neonatal history of respiratory diseases was observed to be a risk factor for hospitalization, since any condition impairing the early postnatal development of the lung predisposes infants to an increased risk of severe bronchiolitis. 
Different papers reported conflicting results about the protective role of breastfeeding on lower respiratory infections. A preliminary analysis conducted on this birth cohort study reported a clear significant reduction of the risk of hospitalization for bronchiolitis associated with breastfeeding (exclusive or in addition to formula milk) [31], confirmed by the analysis performed in the present paper on the entire cohort. The studies by Holberg et al. [32] and Bulkow et al. [33] also described a decreased risk of RSV hospitalization in breastfeeding infants.

Both crowded living conditions and presence of siblings appear to be important risk factors for more severe acute respiratory infections. Reasons include the increased likelihood of exposure to the virus circulation and subsequently the increased risk for infection. In the Canadian PICNIC study [14], the presence of preschool-aged siblings was significantly and independently associated with an increased risk for RSV related hospitalization, and a weaker association was found with the presence of school-aged siblings. Crowded living conditions, defined as 5 or more people living in one household, was also demonstrated to be a significant risk factor for RSV related hospitalization. In some contrast, the Spanish FLIP study [13] revealed that only school-aged siblings and the presence of more than four additional residents and visitors at home were risk factors significantly associated with RSV related hospitalization. In the FLIP-2 study [12], the effect of school-aged siblings was confirmed, however crowded living conditions, identified by the same definition, was not. The Munich RSV Study Group [7], found that siblings at day care attendance significantly augmented the risk for RSV related hospitalization (OR: 3.9; 95 \% CI: 1.9-8.3).

Young age at the beginning of the RSV season is a risk factor for both the development of LRTI as well as hospitalization due to RSV infection. A review of studies of RSV hospitalization rates [23] revealed that approximately $10 \%$ to $28 \%$ of infants hospitalized with RSV are aged below 6 weeks, $49 \%$ to $70 \%$ below 6 months, and $66 \%$ to $100 \%$ below one year.

Moreover, a recent study [34] analyzing hospitalizations for acute respiratory infections in infants $<24$ months reported that the hospitalization rate was higher during the first three months of life and then consistently declined.

The greatest risk factor for hospitalization due to RSV infection appears to be the first few months of life when coincided with the first half of the RSV season. This data was also confirmed by two Spanish studies from the IRIS Group [12, 13] showing that infants with a chronological age below 10 weeks at the onset of the RSV season were at higher risk for RSV related hospitalization. In addition, the majority of hospitalization in our cohort occurred during the first 6 months of life and this result was confirmed focusing the attention in the subgroup of infants born at 33-34 wGA.
This study has some limitations. Firstly, microbiological data to confirm the presence of RSV was available only in $26 \%$ of the cases of hospitalized infants, nevertheless with a percentage of RSV positivity higher than $80 \%$. Previous Italian data [19] are similar to our data (near $15 \%$ of observed clinical bronchiolitis in hospitalized infants were negative when was tested for RSV).

Moreover, a large Italian study conducted on infants $<2$ years hospitalized for LRTI [15] reported that $40.6 \%$ of tested infants were RSV positive and the majority of RSV bronchiolitis occurred in infants $\leq 3$ months.

These data suggest that the rate of etiologic misclassification can be considered low, also because of the age of our study subjects being younger than one year, at which 72-84 \% of cases of bronchiolitis are RSV positive [35].

In addition, a previous study in the UK estimated that around $75 \%$ of unspecified bronchiolitis admissions were RSV related [36]. Globally, it is estimated that only between $4 \%$ and $28 \%$ of children admitted with bronchiolitis are tested for RSV [3].

Considering the statistical analysis, when simultaneously analyzing several covariates, issues about overfitting, interaction and correlation may arise. Different not resolutive approaches and techniques, with relative pros and cons, may be adopted to address these issues. We think the potential overfitting was adequately controlled in our analyses by applying the multi-step selection of the variables that led to a reduced number of predictors entering the final models. Interaction is a complex issue that can be handled with different statistical techniques, none of them exhaustive, among which one of the mostly adopted is the building of mutually exclusive levels in new combined variables, as performed by Escobar et al. [37]. However, in our study no statistically significant interaction was found in the final set of predictors, so we think that the parsimonious models we proposed were appropriate for these analyses.

The strength of this study is that it is the first study to focus on a large longitudinal Italian birth cohort of newborns in order to identify rates and risk factors for hospitalization for bronchiolitis.

This could allow to improve the indications of prophylaxis with palivizumab in infants born at 33 weeks or more (particularly those born at 33-35wGA), reducing both the hospitalizations for acute bronchiolitis and its possible long-term sequelae.

Besides developing particularly serious RSV infections in the first year of life, preterm infants, even those without CLD, are at higher risk for developing recurrent wheezing, asthma [38] and allergic sensitization [39-42] and have persistent abnormal lung function [43]. Moreover in a recent double-blind, placebo-controlled MAKI trial on healthy preterm infants born at a gestational age 
of 33 to 35 weeks, Blanken et al. [44] demonstrated that palivizumab treatment significantly reduces wheezing days during the first year of life, even after the end of treatment.

\section{Conclusions}

The analysis of local epidemiological data and risk factors involved in RSV-related hospitalization is mandatory in order to better plan preventive strategy and to develop updated national guidelines tailored for pediatric high-risk populations. Epidemiological data and a number of underlying risk factors that significantly increase the risk of severe bronchiolitis and subsequent hospitalization rate in this group of infants have been identified in our national birth cohort study, confirming that an infant's individual characteristics and exposure to environmental factors play an important role in determining the risk of severe infection and hospitalization, independently from preterm birth.

The analysis of the weight of each risk factor could allow to define with greater accuracy the risk for bronchiolitis hospitalization for any infant during the first year of life and to take into account the prophylaxis with palivizumab through the determination of "tailored" indications.

\section{Abbreviations}

CHD: Congenital heart disease; CLD: Chronic lung disease; COPD: Chronic obstructive pulmonary disease; GA: Gestational age; LRTI: Lower respiratory tract infections; RSV: Respiratory syncytial virus; SGA: Small for gestational age; WGA: Weeks of gestational age.

\section{Competing interests}

All authors declare that there are no conflict of interests regarding the publication of this paper. Abbvie SRL Italy partially covered the expenses for this study through a research agreement with the Italian National Research Council (CNR). Italian Neonatology Society had no financial involvement for the study.

\section{Authors' contributions}

ML, MM made substantial contributions to conception and design of the study; FP and SDS made substantial contributions to acquisition and analysis of data; FA was involved in analysing the data and in its interpretation; SV and MS were involved in drafting the manuscript and made substantial contributions to interpretation of data. All authors gave significant revision of the draft for important intellectual content and gave final approval of the version to be published.

\footnotetext{
Acknowledgements

We would like to acknowledge Lucy Scioscia and Filippo Filicori for editing this paper.

"Study Group of Italian Society of Neonatology on Risk Factors for RSV Hospitalization": Faldella G, Spinelli M, Corsello G, Gabriele B, La Forgia N, Loprieno S, Boldrini A, Vuerich M, Del Vecchio A, Bertino E, Fabris C, Coscia A Fanos V, Puddu M, Gargano G, Braibanti S, Corso G, Orfeo L, De Luca MG, Paolillo P, Fabiano A, Barberi I, Arco A, Barboni G, Molinari L, Bonomi A, Ladetto L, Carlucci A, Zorzi G, Dall'Agnola A, Girardi E, Di Fabio S, Faccia P, Bottau P, Macagno F, Ellero S, Magaldi R, Rinaldi M, Memo L, Nicolini G, Ngalikpima CJ, Nosari N, Sarnelli P, Parmigiani S, Agosti M, Negri C, Corona MF, Piano F, Scarcella A, Umbaldo A, De Curtis M, Natale F, Aurilia C, Romagnoli C.
}

\section{Author details}

${ }^{1}$ Pediatrics and Neonatology Unit, Imola Hospital, Imola, Italy. ${ }^{2}$ Institute of Biomedical Technologies, National Research Council, Milan, Italy. ${ }^{3}$ Department of Food, Environmental and Nutritional Sciences, University of Milan, Milan, Italy. ${ }^{4}$ Foundation IRCCS Santa Lucia, Rome, Italy. ${ }^{5}$ Neonatology Unit S.Orsola-Malpighi Hospital, Via Massarenti 11, Bologna, Italy. ${ }^{6}$ Pediatric Pulmonology and Allergy Unit, Istituto Giannina Gaslini, Genoa, Italy.

Received: 2 February 2015 Accepted: 18 May 2015

Published online: 26 May 2015

\section{References}

1. Boyce TG, Mellen BG, Mitchel EF, Wright PF, Griffin MR. Rates of hospitalization for respiratory syncytial virus infec-tion among children in medicaid. J Pediatr. 2000;137(6):865-70.

2. Leader $\mathrm{S}$, Kohlhase $\mathrm{K}$. Recent trends in severe respiratory syncytial virus (RSV) among US infants; 1997 to 2000. J Pediatr. 2003;143(5 Suppl):S127-32.

3. Nair H, Nokes DJ, Gessner BD, Dherani M, Madhi SA, Singletoni RJ, et al. Global burden of acute lower respiratory infections due to respiratory syncytial virus in young children: a systematic review and meta-analysis. Lancet. 2010;375(9725):1545-55.

4. Hall CB, Weinberg GA, Iwane MK, Blumkin AK, Edwards KM, Staat MA, et al. The burden of respiratory syncytial virus infection in young children. $N$ Engl J Med. 2009;360(6):588-98.

5. Thorburn K. Pre-existing disease is associated with a significantly higher risk of death in severe respiratory syncytial virus infection. Arch Dis Child. 2009;94(2):99-103.

6. Park HW, Lee BS, Kim AR, Yoon HS, Kim BI, Song ES, et al. Epidemiology of respiratory syncytial virus infection in infants born at less than thirty-five weeks of gestational age. Pediatr Infect Dis. 2012;31(8):99-104.

7. Liese JG, Grill E, Fischer B, Roeckl-Wiedmann I, Carr D, Belohradsky BH. Incidence and risk factors of respiratory syncytial virus-related hospitalizations in premature infants in Germany. Eur J Pediatr. 2003;162:230-6.

8. Carbonell-Estrany X, Figueras-Aloy J, Law BJ. Infección Respiratoria Infantil por Virus Respiratorio Sincitial Study Group; Pediatric Investigators Collaborative Network on Infections in Canada Study Group. Identifying risk factors for severe respiratory syncytial virus among infants born after 33 through 35 completed weeks of gestation: different methodologies yield consistent findings. Pediatr Infect Dis J. 2004;23(11 Suppl):S193-201.

9. Horn SD, Smout RJ. Effect of prematurity on respiratory syn-cytial virus hospital resource use and outcomes. J Pediatr. 2003;143(5 Suppl):S133-41.

10. Welliver RC. Review of epidemiology and clinical risk factors for severe respiratory syncytial virus (RSV) infection. J Pediatr. 2003;143(5 Suppl):S112-7

11. Sommer C, Resch B, Simões EAF. Risk factors for severe respiratory syncytial virus lower respiratory tract infection. Open Microbio J. 2011;5((Suppl 2-M4):144-15.

12. Figueras-Aloy J, Carbonell-Estrany X, Quero-Jiménez J, et al. FLIP-2 Study: risk factors linked to respiratory syncytial virus infection requiring hospitalization in premature infants born in Spain at a gestational age of 32 to 35 weeks. Pediatr Infect Dis J. 2008;27:788-93.

13. Figueras-Aloy J, Carbonell-Estrany X, Quero J, Group IS. Case-control study of the risk factors linked to respiratory syncytial virus infection requiring hospitalization in premature infants born at a gestational age of 33-35 weeks in Spain. Pediatr Infect Dis J. 2004;23:815-20.

14. Law B, Langley J, Allen U, Paes B, Lee DS, Mitchell I, et al. The Pediatric Investigators Collaborative Network on Infections in Canada study of predictors of hospitalization for respiratory syncytial virus infection for infants born at 33 through 35 completed weeks of gestation. Pediatr Infect Dis J. 2004:23:806-14.

15. Lanari M, Giovannini M, Giuffré L, Marini A, Rondini G, Rossi GA, et al. Prevalence of respiratory syncytial virus infection in Italian infants hospitalized for acute lower respiratory tract infections, and association between respiratory syncytial virus infection risk factors and disease severity. Ped Pulmonol. 2002;33:458-65.

16. American Academy of Pediatrics Committee on Infectious Diseases. American Academy of Pediatrics Bronchiolitis Guidelines Committee. Updated guidance for palivizumab prophylaxis among infants and young children at increased risk of hospitalization for respiratory syncytial virus infection. Pediatrics. 2014;134(2):e620-38. 
17. Raccomandazioni della Società Italiana di Neonatologia per la prevenzione delle malattie da virus respiratorio sinciziale (VRS). Acta Neonatologica e Pediatrica 2004;18:19-30

18. Baraldi E, Carraro S, Filippone M. Bronchopulmonary dysplasia: definitions and long-term respiratory outcome. Early Hum Dev. 2009;85(10 Suppl):S1-3.

19. Medici MC, Arcangeletti MC, Rossi GA, Lanari M, Merolla R, Paparatti UD, et al. Osservatorio VRS Study Group. Four year incidence of respiratory syncytial virus infection in infants and young children referred to emergency departments for lower respiratory tract diseases in Italy: the 'Osservatorio VRS' Study (2000-2004). New Microbiol. 2006;29:35-43.

20. Bertino E, Spada E, Occhi L, Coscia A, Giuliani F, Gagliardi L, et al. Neonatal anthropometric charts: the Italian neonatal study compared with other European studies. J Pediatr Gastroenterol Nutr. 2010;51(3):353-61.

21. Baraldi E, Lanari M, Manzoni P, Rossi GA, Vandini S, Rimini A, et al. Inter-society consensus document on treatment and prevention of bronchiolitis in newborns and infants. Ital J Pediatr. 2014;40:65.

22. Shay DK, Holman RC, Roosevelt GE, Clarke MJ, Anderson LJ. Bronchiolitisassociated mortality and estimates of respiratory syncytial virus-associated deaths among US children; 1979-1997. J Infect Dis. 2001;183(1):16-22.

23. Simoes EAF. Environmental and demographic risk factors for respiratory syncytial virus lower respiratory tract disease. J Pediatr. 2003;143:S118-26.

24. Houben ML, Bont L, Wilbrink B, Belderbos ME, Kimpen JL, Visser GH, et a Clinical prediction rule for RSV bronchiolitis in healthy newborns: prognostic birth cohort study. Pediatrics. 2011;127(1):35-41.

25. Kotecha SJ, Watkins WJ, Heron J, Henderson J, Dunstan FD, Kotecha S. Spirometric lung function in school-age children. Effect of intrauterine growth retardation and catch-up growth. Am J Respir Crit Care Med. 2010;181:969-74.

26. Leslie FM. Multigenerational epigenetic effects of nicotine on lung function. BMC Med. 2013;11:27.

27. Joss-Moore LA, Albertine $\mathrm{KH}$, Lane RH. Epigenetics and the developmental origins of lung disease. Mol Genet Metab. 2011;104(1-2):61-6.

28. Nielsen HE, Siersma V, Andersen S, Gahrn-Hansen B, Mordhorst CH, Norgaard-Pedersen B, et al. Respiratory syncytial virus infection: risk factors for hospital admission-a case control study. Acta Paediatr. 2003;92:1314-21.

29. Resch B, Pasnocht A, Gusenleitner W, Müller W. Rehospitalisations for respiratory disease and respiratory syncytial virus infection in preterm infants of 29-36 weeks gestational age. J Infect. 2005;50(5):397-403.

30. Medlock S, Ravelli AC, Tamminga P, Mol BW, Abu-Hanna A. Prediction of mortality in very premature infants: a systematic review of prediction models. PLoS One. 2011;6(9), e23441.

31. Lanari M, Prinelli F, Adorni F, Di Santo S, Faldella G, Silvestri M, et al. Italian Neonatology Study Group on RSV Infections. Maternal milk protects infants against bronchiolitis during the first year of life. Results from an Italian cohort of newborns. Early Hum Dev. 2013:89 Suppl 1:S51-7.

32. Holberg CJ, Wright AL, Martinez FD, Ray CG, Taussig LM, Lebowitz MD. Risk factors for respiratory syncytial virus-associated lower respiratory illnesses in the first year of life. Am J Epidemiol. 1991;133(11):1135-51.

33. Bulkow LR, Singleton RJ, DeByle C, Miernyk K, Redding G, Hummel KB, et al. Risk factors for hospitalization with lower respiratory tract infections in children in rural Alaska. Pediatrics. 2012;129(5):e1220-7.

34. Hall CB, Weinberg GA, Blumkin AK, Edwards KM, Staat MA, Schultz AF, et al. Respiratory syncytial virus-associated hospitalizations among children less than 24 months of age. Pediatrics. 2013;132(2):e341-8.

35. Olabarrieta I, Gonzalez-Carrasco E, Calvo C, Pozo F, Casas I, García-García ML. Hospital admission due to respiratory viral infections in moderate preterm, late preterm and term infants during their first year of life. Allergol Immunopathol (Madr). 2014 Nov 8. doi: 10.1016/j.aller.2014.06.006.

36. Muller-Pebody B, Edmunds WJ, Zambon MC, Gay NJ, Crowcroft NS. Contribution of RSV to bronchiolitis and pneumonia-associated hospitalizations in English children, April 1995-March 1998. Epidemiol Infect. 2002;129(1):99-106.

37. Escobar GJ, Ragins A, Li SX, Prager L, Masaquel AS, Kipnis P. Recurrent wheezing in the third year of life among children born at 32 weeks' gestation or later: relationship to laboratory-confirmed, medically attended infection with respiratory syncytial virus during the first year of life. Arch Pediatr Adolesc Med. 2010;164(10):915-22.

38. Chan KN, Noble Jamieson CM, Elliman A, Bryan EM, Silverman M. Lung function in children of low birth weight. Arch Dis Child. 1989;64:1284-9.
39. Henderson J, Hilliard TN, Sherriff A, Stalker D, AI SN, Thomas HM Hospitalization for RSV bronchiolitis before 12 months of age and subsequent asthma, atopy and wheeze: a longitudinal birth cohort study. Pediatr Allergy Immunol. 2005;16:386-92.

40. Bacharier LB, Cohen R, Schweiger T, Yin-Declue H, Christie C, Zheng J, et al. Determinants of asthma after severerespiratory syncytial virus bronchiolitis. J Allergy Clin Immunol. 2012;130:91-100.

41. Stein RT, Sherrill D, Morgan WJ, Holberg CJ, Halonen M, Taussig LM, et al Respiratory syncytial virus in early life and risk of wheeze and allergy by age 13 years. Lancet. 1999:354:541-5.

42. Sigurs N, Aljassim F, Kjellman B, Robinson PD, Sigurbergsson F, Bjarnason R, et al. Asthma and allergy patterns over 18 years after severe RSV bronchiolitis in the first year of life. Thorax. 2010;65:1045-52.

43. Mai XM, Gaddlin PO, Nilsson L, Finnstrom O, Bjorksten B, Jenmalm MC. Asthma, lung function and allergy in 12-year-old children with very low birth weight: a prospective study. Pediatr Allergy Immunol. 2003;14:184-92.

44. Blanken MO, Rovers MM, Molenaar JM, Winkler-Seinstra PL, Meijer A Kimpen JL, et al. Dutch RSV Neonatal Network. Respiratory syncytial virus and recurrent wheeze in healthy preterm infants. N Engl J Med. 2013;368(19):1791-9.

\section{Submit your next manuscript to BioMed Central and take full advantage of:}

- Convenient online submission

- Thorough peer review

- No space constraints or color figure charges

- Immediate publication on acceptance

- Inclusion in PubMed, CAS, Scopus and Google Scholar

- Research which is freely available for redistribution

Submit your manuscript at www.biomedcentral.com/submit 